\title{
Influential parameters for headed bars in RC beam-column joint
}

\author{
Ajay Chourasia ${ }^{1}$ and Shipali Gupta ${ }^{2, *}$ \\ ${ }^{1}$ CSIR-Central Building Research Institute, Roorkee 247 667, India \\ ${ }^{2}$ Vellore Institute of Technology University, Vellore 632 014, India
}

RC beam-column joint, a critical region of a framed system often does not achieve adequate strength due to poor detailing and workmanship. Conventional anchors such as straight and hooked bars which anchor the flexural longitudinal bar terminating at the joint, have many design and construction drawbacks like steel congestion, leading to honey combing in concrete and difficulties in implementation. This led to the development of headed bars which are highly advocated by researchers, as they provide an alternative solution to conventional anchors. Various parameters such as head geometry, embedment depth, grade of concrete, etc. influence the behaviour of headed bar in the joints. This study presents a review on headed bar for the development of proper guidelines.

Keywords: Anchorage capacity, beam-column joints, headed bars, hooked bar, pull-out capacity.

THE most important aspect of structural design is the anchorage strength of development length reinforcing bars in beam-column joint, which depends on the type of anchorage mechanism. Conventional method used to anchor the longitudinal flexural reinforcing bar terminating at the joint using either the straight bar or the hooked bar, lead to steel congestion, resulting in fabrication difficulties, compaction of concrete, honey combing, problems in the joint strength and other construction difficulties. Headed bar is a potential solution to these problems due to its easy installation, time-saving fabrication, minimization of steel congestion in joints and better concrete placement. Moreover, it ensures that the structural performance is not affected. Headed bars were primarily used in Europe for the construction of offshore oil platform and then expanded to North America, where a large number of headed bars were used on Hibernia platform located in Newfoundland, Canada. These days the demand for headed bar as longitudinal reinforcement and transverse reinforcement for relatively large reinforced concrete structures exposed to high seismic loads is increasing. Headed bar is a mechanical anchorage system with heads attached to the ends of the reinforcing bar. Different types of head attaching techniques such as friction welding, forged welding and threading technique

*For correspondence. (e-mail: shipaligupta16492@gmail.com) are available. Among these, the threading technique is opted most due to proper interlocking between the bar and the head. The ultimate load carrying capacity of the headed bar is influenced by factors such as type of head attaching technique, yield strength of headed bars, diameter of reinforcing bar, concrete compressive strength, head geometry, embedment depth, side cover, and clear spacing between the bars, to some degree, as shown in Figure 1. ACI Committee 408 (development and splicing of deformed bars) and ACI Committee 439 (steel reinforcement) jointly prepared a report on headed bar using tests data from prior studies, which is referred to as ACI 352R-02 whose specification meets that of ASTM A970 for using the headed bar terminating at the junction as a feasible option in disturbed regions of concrete specimens with nonlinear strain distribution. The anchorage capacity of the headed bar installed in the plain concrete is determined using concrete capacity design (CCD) method ${ }^{1}$. The CCD method is basically used to design headed stud anchors in which no bond stress is assumed along the length of the bar and the concrete is assumed as unconfined. No special details of the headed bar are recommended for seismic and non-seismic design ${ }^{1}$.

This paper reviews two decades of research on beamcolumn joint sub-assemblies with headed bar, tested under different loading conditions such as monotonic loading or reversed cyclic loading. Most studies are on concentric beam-column joint and very few on eccentric beam-column joint, used often at the ends and corners of a building. It was observed that the eccentric connection had lower shear strength to some extent due to the existence of slab and transverse beam frames with low confinement, which are more vulnerable to deterioration (side blowout failure). To overcome these difficulties, the possible use of a headed bar in eccentric beam-column joint has to be investigated. Reinforcing bars of large diameter (43 to $57 \mathrm{~mm}$ ) are widely used in the construction of high rise buildings, bridge girder, deep beam and other large members, to eliminate the congestion and fabrication difficulties ${ }^{2}$. Almost all the studies so far are on $36 \mathrm{~mm}$ diameter reinforcing bars. The beam column joints are more vulnerable to seismic load as there is possibility of flexural yielding that leads to plastic hinge formation near joints, which is a initiation of bond deterioration between steel and concrete due to anchorage 
strength at the joints or near the joints. This requires proper detailing of longitudinal bars to prevent the penetration of yielding, thereby weakening the truss mechanism to transfer the shear across the joint core. The plastic hinge formation in the beam-column joint can be eliminated either by shifting the plastic region slightly away from the face of the column, or by increasing the beam depth and longitudinal bar, which is not practical. A practical solution to this has been studied by using the headed bar for relocating the plastic hinge in the beam ${ }^{3}$. A modern mechanical anchorage device, headed bar, has several advantages over the conventional anchorage device, hooked bar. However, few studies on headed bar discuss the need for deep investigation on headed bar for development of proper guidelines for its provision in construction practices. This paper discusses on anchorage devices and stress transmission mechanisms, and the parameters influencing performance of the headed bar-grade of concrete and reinforcing bars, headed geometry, bearing ratio, clear spacing, side cover, embedment depth, development length, confinement and behaviour of headed bars.

\section{Anchorage devices and stress transmission mechanism}

\section{Conventional anchorage device versus modern anchorage device - headed bars}

Hooked bar anchorages are conventionally used for longitudinal beam flexural reinforcing bar terminating within the beam-column joint. The bends and tails of hooked bar promote the development of diagonal compression strut mechanism within the joint, which is the main joint resisting mechanism, while the head plate in the headed bar develops the diagonal compression mechanism ${ }^{4}$. Formation of the bend removes the corrosion resisting layer from the surface of the bar and accelerates corrosion of the bar at the bend ${ }^{5}$. The fabrication of hooked bar is time consuming and demands skilled labour. However, hooked bar leads to steel congestion in a region where main bars of the beam and column pass through or terminate, which hinders the placement and compaction of concrete, resulting in honeycombing ${ }^{5}$. These issues reduce anchorage

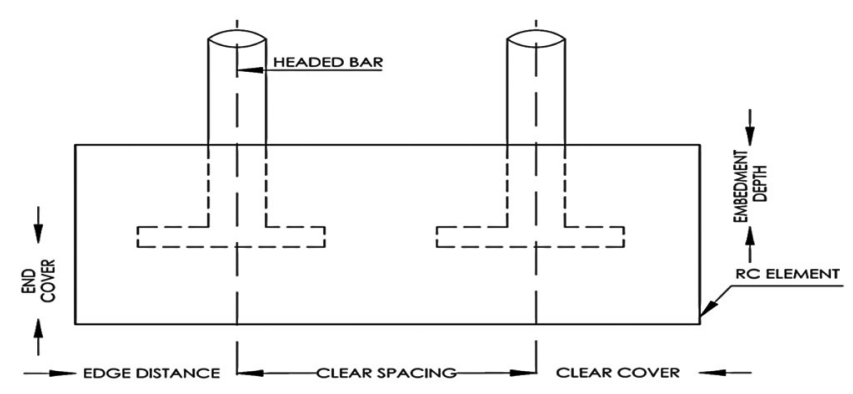

Figure 1. Detail of headed bar embedded into the concrete. strength of the hooked bar, causing early failure of joint in the frames when subjected to seismic load. However, the advantages of headed bar over hooked bar are that it reduces steel congestion when placed exactly at the desired location, saves construction costs, leads to better concrete consolidation, provides full anchorage without cover, offers better bond strength and speed in construction. Hence, it is an efficient form of mechanical anchorage device for beam-column joint ${ }^{5}$.

\section{Stress transmission mechanism}

The adhesion between the reinforcing bar and surrounding concrete is referred to as bond. The bond between steel and concrete ensures strain compatibility and acts as a composite section. The factors responsible for the bond strength between the deformed reinforcing bars and concrete are chemical adhesion, friction and deformation over the surface of reinforcement ${ }^{6}$. The deformed bar provides more efficient bond strength compared to smooth reinforcing bar, as the bond of the smooth bar is negligible, whereas deformation enhances the bond strength ${ }^{1}$. The bond force transfer occurs in two forms: (1) bearing and friction force on the bars and (2) adhesion and friction forces along the surface of the bar (Figure 2). The codes specified hook to anchor the longitudinal bar in beam with minimum embedment length. To develop diagonal compression strut mechanism within the beamcolumn joint, bending of bar for a development length is recommended.

Headed bar consists of the head-bearing component and the bond component, which are equally responsible for the transmission of stress from bar to head and head to concrete. As the stress is applied, the bond component predominantly carries the force, reaches peak bond capacity and subsequently the bar slip increases $(1.5 \%$ to $2.5 \%$ ) with bond deterioration. Subsequently stress transfer to the head bearing component leads to failure $(2.5 \%$ to $6 \%$ drift) at the peak anchorage capacity, which implies that the anchorage capacity of the headed bar is a combination of bond contribution and head bearing contribution ${ }^{6}$. However, the bearing of head provides greater resistance compared to the bond component. Further, the occurrence of crack formation at the interface of the

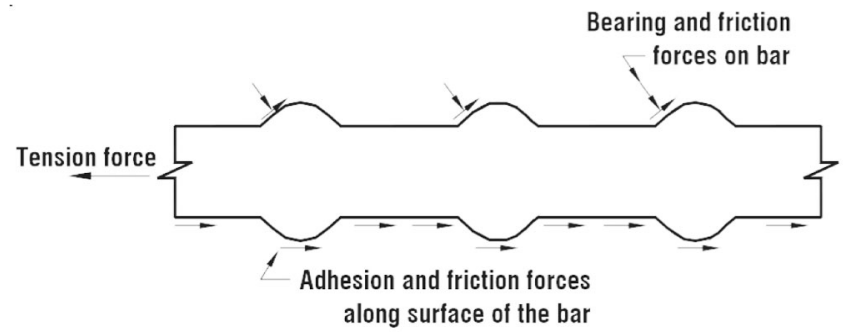

Figure 2. Stress transfer mechanism between rebar and concrete. 
beam-column joint and in the joint core results in bond deterioration ${ }^{7}$.

\section{Influencing parameters on performance of headed bar}

\section{Grade of concrete and reinforcing bars}

The specified yield strength of headed bar and compressive strength of concrete are limited to $420 \mathrm{MPa}$ and $41 \mathrm{MPa}^{1}$, whereas the specified strength of headed bar and concrete strength are recommended up to $540 \mathrm{MPa}$ and $100 \mathrm{MPa}$ (ref. 7), which results in satisfactory performance for both low seismic risk and moderate and high seismic risk joint with headed bars. A test was performed on headed bar using high strength steel (815 MPa), which exhibited low strength in beam-column joint due to lack of development length. A large diameter of the bar is not feasible for the joint design criteria (very large dimension) of beam or column. High strength bars of diameter $43 \mathrm{~mm}$ and $57 \mathrm{~mm}$ were permitted for the design of bridges and nuclear plants ${ }^{8}$. Members subjected to flexural hinging followed by modest joint deterioration are allowed maximum permissible size of the deformed bar, i.e. $36 \mathrm{~mm}$ and normal weight concrete ${ }^{7}$. All these recommendations are not applicable to light weight concrete due to lack of experimental data. To promote favourable anchorage behaviour in the beam-column joint, high strength reinforcement $(690 \mathrm{MPa})$ should be combined with high strength concrete $(100 \mathrm{MPa})^{9}$. Researchers observed that increase in grade of concrete for constant embedment depth increases the bond capacity of the headed bar (Table 1$)^{10}$.

\section{Head geometry and bearing ratio}

Previous studies on headed bar in Europe, Canada and the United States have revealed that the head area should be 3 times the nominal bar area ${ }^{7,11}$. The geometry of the head is responsible for the transfer of full rebar force into

Table 1. Influence of grade of concrete on bond capacity of headed bar ${ }^{10}$

\begin{tabular}{lcc}
\hline $\begin{array}{l}\text { Grade of } \\
\text { Concrete }\end{array}$ & $\begin{array}{c}\text { Embedment } \\
\text { depth }(\mathrm{mm})\end{array}$ & $\begin{array}{c}\text { Bond } \\
\text { capacity }(\mathrm{kN})\end{array}$ \\
\hline M20 & 200 & 55 \\
M30 & & 120 \\
M40 & & 140 \\
M20 & 240 & 160 \\
M30 & & 190 \\
M40 & & 220 \\
M20 & 280 & 200 \\
M30 & & 220 \\
M40 & & 230 \\
\hline
\end{tabular}

multi-axial stresses in concrete beneath the head, without crushing or bending the head. Among the various head plate shapes like circular, elliptical, rectangle and square as shown in Figure $3 a$, the most efficient shape is found to be circular shape head plate $^{12}$. The pull-out resistance of different head geometries for bearing ratio ranging from 6 to 8 varies a lot. For a bearing ratio of 6 , effective pull-out capacity of circular $>$ square $>$ rectangle head, which is greater than that specified in ACI381-08 (ref. 13). A large head plate of headed bar means large angle of anchor inclination near the concrete surface along with large surface area failure ${ }^{12}$. At failure, the bond stress decreases with increase in the relative head area because, large relative head area takes long time to transfer the bond stress to the head and decline. Also, slip of the head reduces with relative head area before the head has attained its maximum capacity, and then increases steadily till failure ${ }^{4}$. No minimum criteria is specified for the net bearing ratio ${ }^{14}$. It is well understood that after bond deterioration the anchorage relies on the area of the head bearing because, it is not necessary that large head size warrants a shorter development length to ensure adequate bond behaviour at low to moderate drift levels ${ }^{14}$. Headed bar with a net bearing ratio greater than 4 is considered as a large head which exhibit higher anchorage strength. However, it is impracticable compared to the small head with net bearing ratio less than 4 $\left(A_{\mathrm{brg}} / A_{\mathrm{b}}=2.6\right)$, which relieves the congestion problems and minimizes the column bar obstruction while inserting the beam bar into the column cage. The head thickness of $1 \mathrm{db}$ ensures effective head bearing strength with small deformation in steel ${ }^{5}$. A test on eccentric beam-column joint with double headed bar attached on each beam bar within the joint (Figure $3 b$ and $c$ ), oriented in staggered pattern showed higher anchorage capacity, preventing the push out on the back of the core. This also reduces the yield penetration and bond deterioration along the beam bar in the joint, thereby delaying degradation of shear capacity beyond the limiting drift ratio of $4 \%$ (ref. 15). Further, based on research, the design of the headed bar with net bearing ratio greater than 4 was found to be appropriate to ensure anchorage strength both in elastic and inelastic deformation. This introduces a provision for obstruction or interruption of bar deformation, which should not extend more than $2 \mathrm{db}$ (diameter of bar) from the bearing face of the head (Figure 4) ${ }^{1}$. The net head bearing area, which is the difference between head area and bar area, obtained by subtracting obstruction area from head area, is often absent in many cases.

Detailing single headed bar with large diameter of deformed bar is disadvantageous compared to detailing single headed bar with small diameter of deformed bar. A single headed large diameter bar causes splitting of cover along the bar with the generation of high compressive stress at the vicinity of the heads and leads to diagonal cracking $^{2}$. 

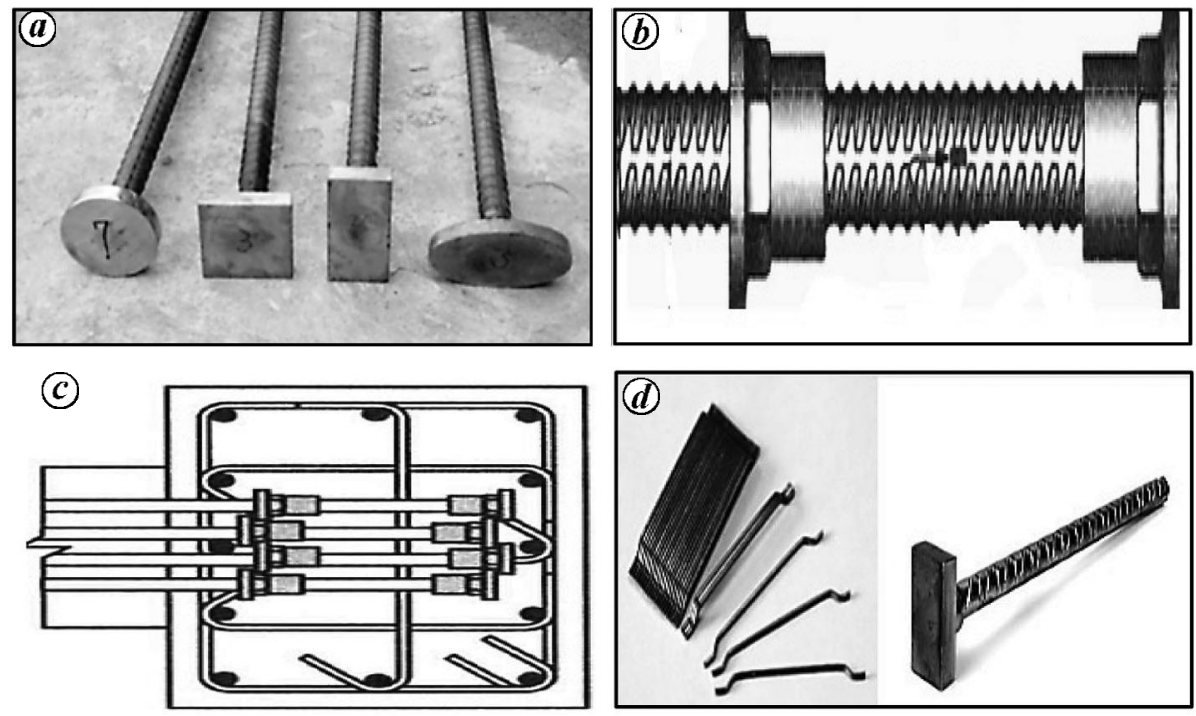

Figure 3. $\boldsymbol{a}$, Different head geometry ${ }^{12} ; \boldsymbol{b}$, Double headed $\operatorname{bar}^{16} ; \boldsymbol{c}$, Arrangement of double headed bar in staggered pattern ${ }^{16} ; \boldsymbol{d}$, Steel fibre and headed $\mathrm{bar}^{17}$.

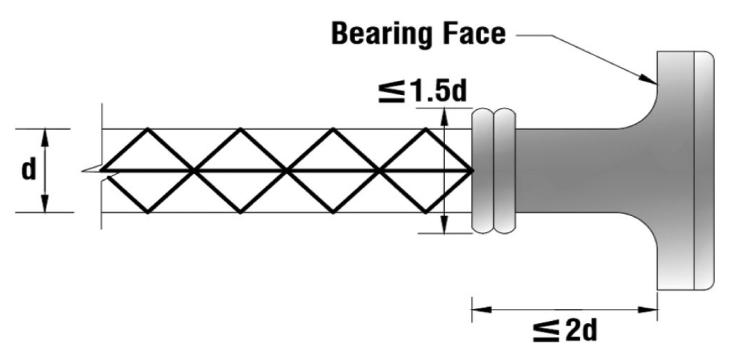

Figure 4. Obstruction and interruption for headed bars.

Inadequate transverse reinforcement due to congestion at the joint resulted in brittle shear failure. Concrete mix incorporated with $2 \%$ steel fibre at beam-column joint using headed bar is shown in Figure $3 d$ and exhibits $45 \%$ higher ductility, stiffness and anchorage ${ }^{16}$.

\section{Headed bar clear spacing, side clear cover and edge distance}

ACI352R-02 recommends a cover of $50 \mathrm{~mm}$ headed bar from the back of the joint core where concrete bearing capacity is higher in the diagonal compression strut. The restraining reinforcement is provided at beam-column joint to prevent the prying action of the headed bar placed near the concrete cover. The ultimate load carrying capacity of the headed bar also depends on its location, i.e. edge bar, centre bar or corner bar, among which centre bars exhibit higher strength due to large area of failure surface, while the cover bars exhibit the least strength ${ }^{17}$. In the case of multiple headed bar, the spacing between the headed bar and edge distance is provided to prevent the interaction between the bars during load application ${ }^{12}$.

A side clear cover of minimum $2 \mathrm{db}$ is required primarily to protect the reinforcement against extreme weather and fire while $35 \mathrm{~mm}$ is specified for the head ${ }^{14}$.
Clear spacing of the bar is an important aspect in the design and detailing of the beam, based on which the size and dimensions of the beam are determined. ACI318-08 recommends that clear spacing between the headed bar should be more than $4 \mathrm{db}$ which is determined using lower bound values obtained from various lap splice tests. This value is significantly larger than the value $(1 \mathrm{db}$ or $1.5 \mathrm{db}$ ) required conventionally in beams and column. This conservative limitation is adopted to prevent the overlap of concrete cone failure surface area around the headed bar under tension. A study on clear spacing of $1.5 \mathrm{db}, 2 \mathrm{db}, 2.25 \mathrm{db}$ and $4.25 \mathrm{db}$ showed that at $4.25 \mathrm{db}$ clear spacing, the degree of flexural yielding was small at the bar ends and higher at the critical section, whereas in the other cases the concrete deformation exceeded the yield strain at the end of the bars ${ }^{18}$. A clear spacing (of greater than $4 \mathrm{db}$ ) between the bars is impractical and it commonly ranges between $1 \mathrm{db}$ and $3 \mathrm{db}$ in practice. Clear cover of $3.6 \mathrm{db}$ and clear bar spacing of $4.2 \mathrm{db}$ show no effect on the seismic performance of the headed bar in the beam-column joint. This is accomplished by reducing the amount of head restraining reinforcement ${ }^{14}$.

The multi-layer reinforcing bar, where the spacing between the bars determines the failure surface, showed no influence on the lateral resistance of beam-column joint $^{14}$. ACI 318-14 strictly recommends a minimum clear spacing of $3 \mathrm{db}$ which is adopted mostly in the design and detailing of the flexural member.

\section{Embedment depth}

Embedment depth is the overall depth of the bar through which the force is transferred to or from the surrounding concrete, while effective embedment depth is the distance from the bearing surface of the head ${ }^{14}$. A ratio of 


\section{REVIEW ARTICLES}

embedment depth to clear cover of less than 5 is termed as shallow embedment depth, while a ratio greater than 5 is termed as deep embedment depth (Figure 5). The ultimate load carrying capacity of headed bar is enhanced by the embedment depth, which determines the size of the pull-out concrete cone failure surface $\operatorname{area}^{18}$. A closely spaced multiple headed bar deeply embedded in the reinfored concrete column (10, 13 and $15 \mathrm{db})$ with minimum column tie spacing $(3,4.5,6$ and $9 \mathrm{db})$ for different diameters of deformed bar $(16,22,25$ and $29 \mathrm{~mm}$ ) showed that the pull-out strength of the individual headed bar increases by over $125 \%$ of the yield strength of the bar $^{19}$. A test that was performed on a beam-column joint designed for joint shear requirement with an embedment depth 1.5 to 2 times the development length of headed bar resulted in less head bearing demand $^{14}$. The beam-column joint consisting of the headed bar with a small head, with a development length of $15 \mathrm{db}$ is capable of transferring moments and forces in the member without drift loss up to $3.5 \%$. Larger embedment depth $(8.4,12$ and $16 \mathrm{db})$ with smaller bearing ratio resulted in higher bond strength ${ }^{13}$. The embedment depth decides the failure behaviour of the headed bar. A larger embedment depth leads to yielding of the bar, whereas a smaller embedment depth leads to splitting of the concrete. A large embedment depth with large diameter of bar and side cover promotes the anchorage behaviour and side blowout capacity of the headed bar.

\section{Development length}

The minimum length of the reinforcing bar required to develop bond strength to resist external tensile load is referred to as development length, which is composed of bonded length and bearing length. When there is insufficient space for provision of bonded length of the bar, the bar is terminated in the form of a hook or head which adds the bearing force to the bond force.

For the design of a hooked bar, the development length for flexure longitudinal bar in tension is categorized based on the critical section, subjected to low seismic risk (eq. (1)) and moderate to high seismic risk (eq. (2)) beam-column connection ${ }^{7}$ as defined

$$
\begin{gathered}
l d h=\frac{f_{y} d b}{4.2 \sqrt{f_{c}^{\prime}} \phi}, \\
l d h=\frac{a f_{y} d b}{6.2 \sqrt{f_{c}^{\prime}} \phi},
\end{gathered}
$$

where $f_{y}$ is the specified strength of the headed bar, $d b$ the diameter of the reinforced bar, $f_{c}^{\prime}$ the specified compressive strength of concrete, $\phi$ the strength reduction factor, $\alpha$ the stress multiplier for longitudinal reinforcement at joint/member interface, $l d h$ the development length of hooked bars in mm.

The development length of headed bar is 0.67 times the corresponding length of hooked bar indicating no significant loss of anchorage due to deterioration of joint under cyclic loading ${ }^{7}$. The development length of headed bar in tension as shown in Figure 6 is given by ${ }^{1}$

$$
l \mathrm{~d} t=\frac{0.19 \psi_{e} f_{y} \mathrm{~d} b}{\sqrt{f_{c}^{\prime}}} \geq \text { the larger of } 8 \mathrm{db} \text { and } 152 \mathrm{~mm}
$$

where $f_{y}$ is the specified strength of the headed bar, $d b$ the diameter of the reinforced bar, $f_{c}^{\prime}$ the specified compressive strength of concrete, $\psi_{e}=1.2$ for epoxy coated reinforcement and 1 for other. $l d t$ the development length of the headed bar in mm.

Generally, the load distribution along the development length was assumed constant ${ }^{7}$. This assumption no longer found to be constant because the load distribution depends on the bonded length of headed bar. For more bonded length, the majority of the load is resisted by bonded length followed by slip of the bar, and the remaining load is borne by bearing length ${ }^{20}$.

\section{Anchor reinforcement and confinement in beam-column joint}

The anchor reinforcement transfers the force from the anchors into the structural member; the best example is hairpins ${ }^{1}$. Various studies have revealed that column main reinforcement and column ties influence the strength and ductile behaviour of the headed bar. Column ties close to the headed bars develop large strain but contribute to the pull-out capacity whereas column ties that

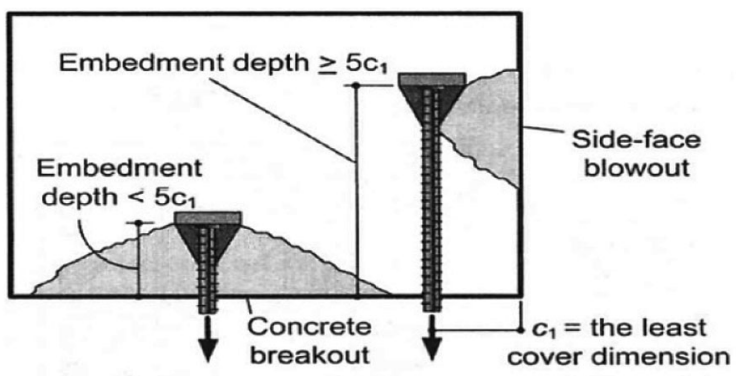

Figure 5. Shallow embedment depth versus deep embedment depth ${ }^{15}$.

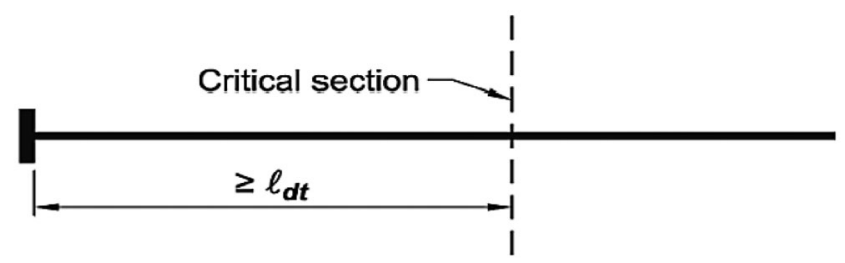

Figure 6. Development length of headed $\operatorname{bar}^{26}$.

CURRENT SCIENCE, VOL. 116, NO. 10, 25 MAY 2019 
are away from the headed bar develop small strain but do not contribute to the pull-out capacity.

The seismic performance of headed bar with moderate joint confinement does not adversely influence the anchorage capacity of the inter-storey joints. This is because the external truss above the joint provides different bearing stress transfer paths resulting in the reduction in transverse reinforcement while placing the headed bar as a beam longitudinal reinforcement ${ }^{5}$. A test on the beam-column subassemblies with T-headed bar in combination with $\mathrm{X}$-cross bar and hairpins as transverse reinforcement (Figure 7) was performed. The results showed enhancement in the ultimate strength by $10 \%$, ductility by $12 \%$, stiffness by $15 \%$ and much better crack control capacity. This assisted in alleviating congestion of steel, easy pouring of concrete and faster construction in the site $^{21}$.

The confinement of the longitudinal headed bar and lap splices in the beam-column joint influenced the flexural behaviour of the member to a large extent. In general, lap splices fail a priori to the longitudinal bar. The lap splices ranging from $15 \mathrm{db}$ to $25 \mathrm{db}$ were placed in various confinement patterns (unconfined, locally confined and standard confined) to eliminate the prying action and to increase the end bearing capacity. Standard confined lap splices contributed $73 \%$ increase in the end bearing capacity $^{22}$. The use of U-shaped reinforcing bar and stick type bar for proper confinement of headed bar in the exterior beam-column joint shown in Figure 8 provides proper confinement to the main headed bar, which reduces the stress in concrete cover, enhances the bond

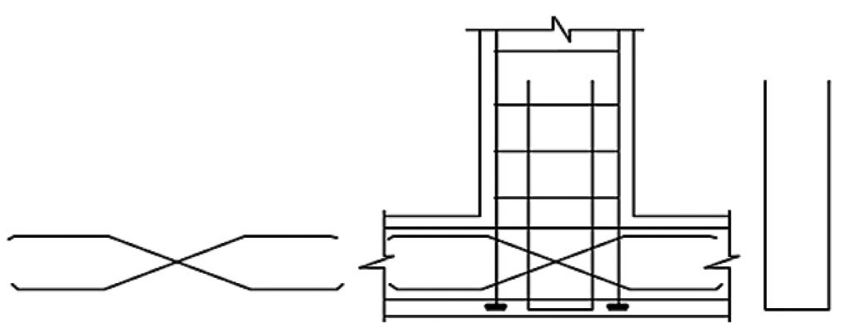

Figure 7. Detailing of beam-column joint using headed bar with $\mathrm{X}$ cross bars and hairpins.

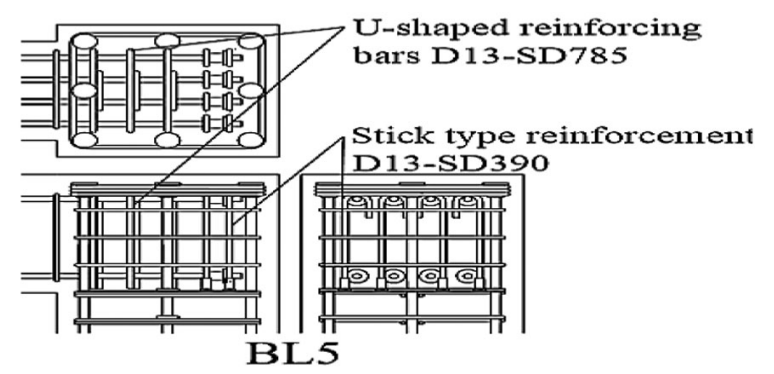

Figure 8. Arrangement of U-shaped reinforcing bar and stick type reinforcement in beam-column joint ${ }^{23}$. strength and eliminates the diagonal cracking due to storey shear ${ }^{23}$. Closely spaced, high strength headed bar in a special moment frame subjected to cyclic loading was tested with different confinement criteria. It was found that the ties provided at the column main bar in the joint at a spacing of $75 \mathrm{~mm}$ promote better anchorage performance and delay in joint deterioration than $125 \mathrm{~mm}$ spacing ties in the joint ${ }^{9}$. Transverse reinforcement as hairpin bars enhanced the anchorage capacity of headed bars, limited the splitting crack failure arising from the bond stresses and confined the head bearing as shown in Figure 9 (ref. 22).

\section{Behaviour of headed bars}

Beam-column joint subassemblies fail in different patterns under reversed cyclic loading, which are categorized on the basis of performance indices such as: category I: beam-column flexural failure followed by modest joint deterioration. category II: beam-column flexural failure followed by joint failure and category III: joint failure prior to headed bar yielding. Premature joint failure generally occurs earlier than flexural failure when the ratio of peak moment to negative moment is less than 1 or, no flexural yielding is observed before the last cycle of the test $\mathrm{t}^{24}$. The strength of head anchor under tension depends on the material properties and dimension of the head. Deformation developed in the part of headed bar close to the applied load is generally larger than that in the part of headed bar close to the head plate. The difference in deformation indicates that the bond between the headed bar and concrete is not broken at the peak load and the anchorage relies on the head bearing along with the bonded bar. The failure in the headed bar was induced as a result of the tension forces. The failure modes of headed bars associated with the anchorage of the head are as follows (Figure 10):

(a) Yielding of the bar generally takes place in case of large, deep embedment depth. The yielding mechanism begins when the applied load on headed bar exceeds the yield strength of the bar with the occurrence of a small slip, causing breaking of the top concrete conical surface (Figure $10 a$ ).

(b) Pull-out failure or bond failure occurs due to insufficient bond between the bonded length and surrounding concrete. Small embedment depth does not

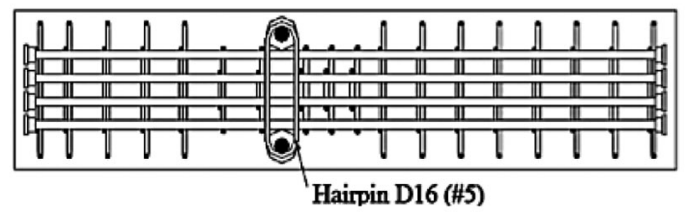

Figure 9. Arrangement of hairpins transverse reinforcement in beamcolumn joint ${ }^{22}$. 

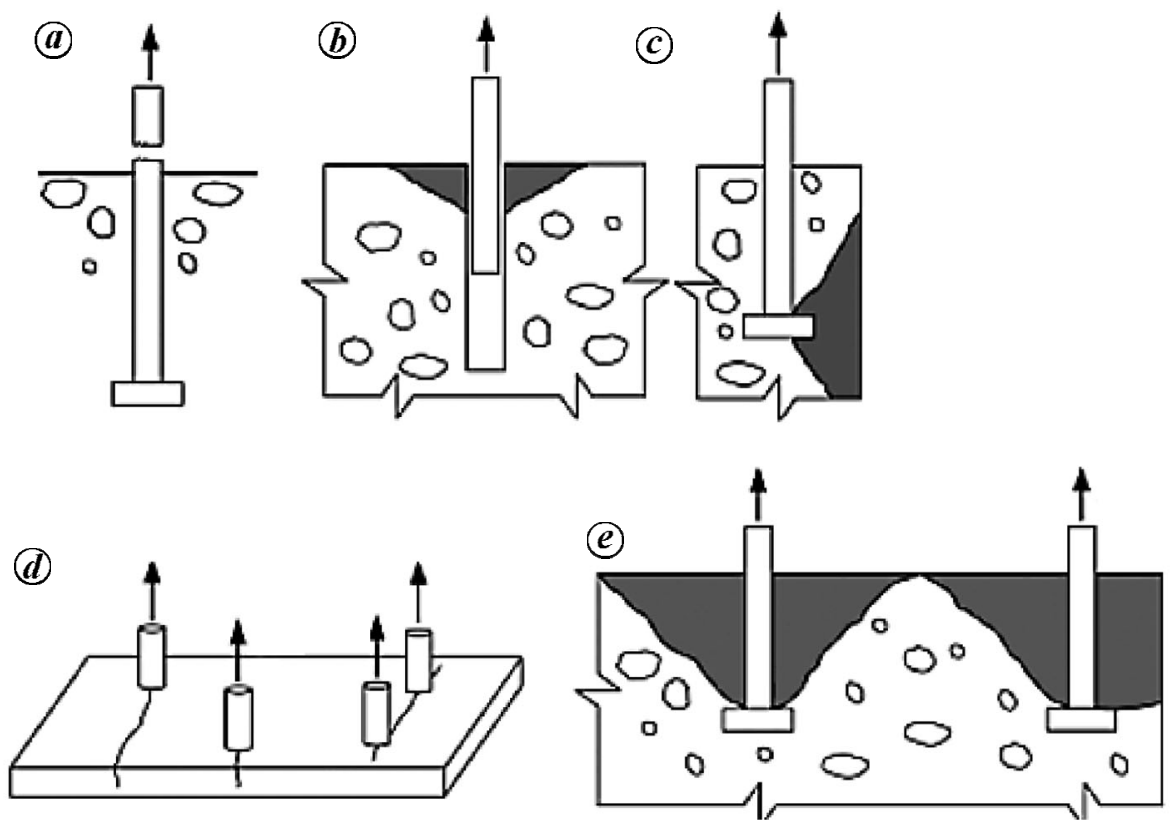

Figure 10. Different types of failure modes of headed bar ${ }^{1}$ : (a) Bar yielding failure, (b) Pull-out failure, (c) Side blow out failure, $(\boldsymbol{d})$ Concrete splitting, (e) Concrete breakout failure.

contribute to a proper bond between the bar and concrete resulting in failure of the bond (Figure $10 \mathrm{~b}$ ).

(c) Side blow out failure occurs when the cover to the headed bar is inadequate (Figure $10 c$ ).

(d) Concrete splitting failure is the diagonal cracking in the beam-column joint. It occurs due to lack of confinement of headed bar and insufficient concrete surface area to distribute the bond stress across the headed bar. In a single headed bar, the bond stress on the concrete from the bearing plate exceeds the concrete bearing capacity, resulting in concrete splitting failure (Figure $10 d)^{22}$.

(e) Concrete breakout failure occurs in heads due to no reinforcement provision to redirect the stress path back to the concrete mass ${ }^{25}$. The head is a steel bearing plate that not only transfers the bond stress along the bar, but is also subjected to large bearing pressure on its face. When this bearing pressure exceeds the concrete bearing capacity, the concrete cone shaped failure occurs (Figure $10 e)^{18}$.

\section{Conclusion}

Headed bar has proven to be an efficient mechanism compared to the conventional anchorage system, i.e. the straight or hooked bar. It has various advantages over conventional anchors such as reduced steel congestion in the joint, improved strength, and speed to construction and economy. Hence, the following conclusions have been made through the knowledge gained from prior studies on the design of beam-column joint using headed bar: (i) High strength reinforcing bar and high strength concrete enhance the anchorage behaviour of the headed bars. (ii) The head geometry determines the ultimate capacity of headed bar with the circular shaped headed bar proving to be the most effective compared to rectangular, square and elliptical shaped headed bar. (iii) The load distribution ratio of the development length bar varies with the bonded length and increase in the bonded length reduces the slip of the bar. (iv) The single headed bar with deformed bar diameter varying from $16 \mathrm{~mm}$ to $29 \mathrm{~mm}$ and embedment depth ranging from $8 \mathrm{db}$ to $12 \mathrm{db}$ enhanced the pull-out resistance by $95 \%$ of the bar yield load. (v) Increase in the development length, head size and thickness, and decrease in the joint shear demand resulted in a better performance of the joint. (vi) Closely spaced headed bars $(1.5 \mathrm{db}$ to $2.25 \mathrm{db})$ were found to be effective with no severe failure. Hence, clear spacing less than $2 \mathrm{db}$ is acceptable for headed longitudinal bars. (vii) The multiple headed bar with large embedment depth and small tie spacing in the reinforced concrete column increases the pull-out resistance by $17.7 \%$ on an average. (viii) Large embedment depth, edge distance, and head spacing with small tie spacing in the column, contribute to an increase in the pull-out capacity. Quantification of these various parameters for design and detailing has not been dealt with properly in previous studies. The application of the headed bar in precast beam column joint as well as in light weight concrete may come to scope in construction practices in future.

1. ACI Committee, American Concrete Institute and International Organization for Standardization, Building code requirements for 
structural concrete (ACI 318-08) and commentary. American Concrete Institute, 2008.

2. Mihaylov, B. I., Bentz, E. C. and Collins, M. P., Behavior of deep beams with large headed bars. ACI Struct. J., 2013, 110, 1013.

3. Chutarat, N. and Aboutaha, R. S., Cyclic response of exterior reinforced concrete beam-column joints reinforced with headed bars experimental investigation. ACI Struct. J., 2003, 100, 259-264.

4. Thompson, M. K., Ziehl, M. J., Jirsa, J. O. and Breen, J. E., CCT nodes anchored by headed bars - Part 1: behavior of nodes. $A C I$ Struct. J., 2005, 102, 808.

5. Kang, T. H., Ha, S. S. and Choi, D. U., Bar pull-out tests and seismic tests of small-headed bars in beam-column joints. $A C I$ Struct. J., 2010, 107, 32.

6. Subramanian, N., Development length of reinforcing bars: need to revise Indian codal provisions. Indian Concr. J., 2005, 79, 39-46.

7. ACI-ASCE Committee 352, Recommendations for design of beam-column connections in monolithic reinforced concrete structures (ACI352R-02), American Concrete Institute, Farmington Hills, Michigan, US, 2002.

8. ASTM A970/A970M-07 standard specification for headed steel bars for concrete reinforcement, ASTM International, West Conshohocken, Pa, 2007.

9. Chang, C. J., High-strength reinforcement in exterior beam-column joints under cyclic loading. ACI Struct. J., 2017, 114, 1325.

10. Gond, S. and Kulkarni, S. M., Bond strength behaviour of headed reinforcement bar with varying embedment length. 6th International Conference on Structural Engineering and Construction Management, Kandy, Sri Lanka, 2015.

11. ASTM A970/A970M-98, Standard Specification for Headed Steel Bars for Concrete Reinforcement, ASTM International, West Conshohocken, PA, 1998.

12. Park, H. K., Yoon, Y. S. and Kim, Y. H., The effect of head plate details on the pull-out behaviour of headed bars. Mag. Concr. Res., 2003, 55, 485-496.

13. Kawale Abhijit and Patil Yogesh, D., Pull-out capacity and bond behaviour of headed reinforcement in concrete. Int. J. Innov. Res. Sci., Eng. Technol., 2016, 5, 12114-12119.

14. Kang, T. H., Shin, M., Mitra, N. and Bonacci, J. F., Seismic design of reinforced concrete beam-column joints with headed bars. ACI Struct. J., 2009, 106, 868.

15. Lee, H. J. and Yu, S. Y., Cyclic response of exterior beam-column joints with different anchorage methods. ACI Struct. J., 2009, 106, 329.

16. Soumya, A. T. and Bini, B., Alternate ductile detailing for beam column joints. SSRG Int. J. Civil Eng., 2017, 94-97.

17. Bakir, P. G. and Boduroglu, M. H., The ultimate load carrying capacity of concrete members with headed bars. 27th Conference on Our World in Concrete and Structures, 2002.

18. Lam, K. M., Kim, W. S., Van Zandt, M. and Kang, T. H., An experimental study of reinforced concrete beams with closelyspaced headed bars. Int. J. Concrete Struct. Mater., 2011, 5, 7785.
19. Choi, D. U., Test of headed reinforcement in pullout II: deep embedment. Int. J. Concr. Struct. Mater., 2006, 18, 151-159.

20. DeVries, R. A., Load distribution between bond and end-bearing for hooked and headed bars in concrete. In $A E I, 2015,269-227$.

21. Rajagopal, S. and Prabavathy, S., Seismic behavior of exterior beam-column joint using mechanical anchorage under reversal loading: an experimental study. IJST-T Civ. Eng., 2014, 38, 345.

22. Chun, S. C., Choi, C. S. and Jung, H. S., Side-face blowout failure of large-diameter high-strength headed bars in beam-column joints. ACI Struct. J., 2017, 114, 161.

23. Tasai, A., Kusunoki, K., Kiyohara, T. and Adachi, T., Structural performance of reinforced concrete roof exterior beam column joint with headed bars. In Proceedings of the 15th World Conference on Earthquake Engineering, Lisboa, 2012.

24. Kang, T. H. K., Recommendations for design of RC beam-column connections with headed bars subjected to cyclic loading. Proc. 14WCEE, 2008.

25. Thompson, M. K., Jirsa, J. O. and Breen, J. E., CCT nodes anchored by headed bars-Part 2: capacity of nodes. ACI Struct. J., 2006, 103, 65 .

26. Mancuso, C. and Bartlett, F. M., ACI 318-14 criteria for computing instantaneous deflections. ACI Struct. J., 2017, 114, 1299.

\section{Further reading:}

1. DeVries, R. A., Jirsa, J. O. and Bashandy, T., Anchorage capacity in concrete of headed reinforcement with shallow embedment. $A C I$ Struct. J., 1999, 96, 728-737.

2. Chaim, D. U., Hongzl, S. G. and Lee, C. Y., Test of headed reinforcement in pull-out. KCI Concrete J., 2002, 14, 1102410.

3. Van Mier, J. G. M., Ruiz, G., Andrade, C. and Yu, R. C., Anchorage strengths of lap splices anchored by high-strength headed bars.

4. Kang, T. H. K. and Mitra, N., Prediction of performance of exterior beam-column connections with headed bars subject to load reversal. Eng. Struct. J., 2012, 41, 209-217.

5. ACI 408 Committee, Bond and Development of Straight Reinforcing Bars in Tension (ACI 408R-03). American Concrete Institute, Detroit, Michigan, US, 2003, p. 49.

ACKNOWLEDGEMENTS. The study was conducted as a part of the research programme at CSIR-Central Building Research Institute, Roorkee, India. The author thanks the Director, CSIR-CBRI for permission to publish the paper and to the reviewers of this paper for their suggestions.

Received 19 January 2018; revised accepted 18 February 2019

doi: $10.18520 / \mathrm{cs} / \mathrm{v} 116 / \mathrm{i} 10 / 1666-1673$ 